\title{
SYPHILITIC DISEASES OF THE EYE
}

\section{Discussion}

Dr. B. B. Sharp said he felt he was not in disagreement with anything which had been said in the papers. Admittedly interstitial keratitis was an awkward condition to treat, and he believed the idea that bismuth and arsenic were of no use, for it was due to the fact that interstitial keratitis might occur during treatment in patients who had not had it before, or when the first eye was being treated it might occur in the other eye. He had seen many of these cases at Great Ormond Street Children's Hospital, and that was the experience. And there were a number of cases in which the Wassermann was negative from the outset, but in each of these cases a syphilitic infection of the family was proved, or the Wassermann had become negative after treatment before the interstitial keratitis arose. And it was the experience there that the interstitial keratitis was not so severe when it occurred during treatment as otherwise, and the sequel was not so grave. In some cases, indeed, it cleared up without leaving any trace.

He asked whether there was any local treatment, such as injection under the conjunctiva, that was of use in these cases. He had heard of operations being done on the cornea to reproduce a transparent window, but he did not know of results from such a procedure.

Dr. T. Anwyl Davies wished to congratulate the openers on their papers; he had learned much from them. He could not remember a case in which, though treatment was commenced in some patients fairly soon, the second eye was not affected. In certain cases he had tried a very mild stimulating dose of X-rays, and had found the effect on the photophobia very rapid, for within a few hours it had disappeared. Whether in those instances the keratitis itself disappeared more rapidly in consequence of the rays he did not know. He would like to hear of any other members' experience of X-rays in these cases, and whether the prognosis was improved by their use. 


\section{SYPHILITIC DISEASES OF THE EYE}

Mr. John ADAms asked how early syphilitic eye disease could be detected, and with what frequency it could be found in children affected with syphilis. It could not be very common; he seldom saw it. The great drawback in treating cases of congenital syphilis, in children not born in a hospital, was that there occurred such a delay before treatment was commenced. If the treatment of a syphilitic child was commenced as soon as the child was born, very seldom any secondary disease was seen. He had under observation children over twelve years of age who were treated from the time of their birth-they stood the treatment extremely well-and the results were excellent. Choroiditis, iritis and keratitis were extremely rare. The effect of salvarsan could be seen the same day treatment commenced; one did not have to wait days to see improvement. On the previous day he gave an injection to a very severe case of syphilis, and saw the patient half an hour later, and by that time she had developed a marked Herxheimer rash all over the body, thus showing the rapid action of salvarsan. The great point, especially in young syphilitic babies, was to commence the treatment as quickly as possible. The dose should be graduated, according to the weight of the patient. Practically all these cases got well. He had had opportunities of watching his cases from birth until some years after, and they appeared as healthy as ordinary children and developed no manifestation of syphilis.

Dr. S. C. Woodhouse said he had wondered whether there was more association between neural syphilis and early eye changes than was usually thought ; many cases of secondary iritis were associated with a positive Wassermann in the cerebro-spinal fluid, and under thorough treatment these cases did well. The Wassermann reaction of the cerebro-spinal fluid became negative about the same time as that of the blood.

Mr. HAMish Nicoll expressed his great interest in the opening papers. In the table distributed by Mr. Browning, in which the result of the Wassermann test was given, he would like to know whether the reference was to blood tests only. (Mr. Browning: Only the blood Wassermann.) Was it not likely that the cerebro-spinal fluid might be positive? Some people objected to treat cases of syphilis with arsenic if there were eye troubles, 


\section{BRITISH JOURNAL OF VENEREAL DISEASES}

especially irido-cyclitis. He would like an authoritative statement as to whether there were any eye diseases which it was dangerous to treat with arsenic.

Colonel HARRISON said it was interesting in connection with the causation of interstitial keratitis that both openers had spoken of the association with injury. $\mathrm{He}$ (Colonel Harrison) had always been convinced that injury was a potent factor in precipitating interstitial keratitis just as it was in other parts of the body. During the war, as Dr. Browning would remember, they had a fairly large number of adult cases of interstitial keratitis at the Rochester Row Military Hospital, and he felt sure that in these cases the precipitating agent had been exposure under active service conditions. Some years ago he had expressed his views on this matter before a Committee of Inquiry, and had been surprised to be contradicted by an ophthalmic surgeon. He had often wondered why the other eye so often became affected. It seemed to him analogous to the case in other parts of the body where a tertiary lesion develops ; for example, at one spot on the skin which has been the seat of a trivial injury, but spreads far beyond this area. Was it because the spirochætes, having broken down the resistance of the tissues and so acquired an increased virulence, spread to the neighbouring tissues, or was it because neighbouring tissues had their resistance lowered and the spirochætes located there got the upper hand? With regard to treatment, he recalled that some years ago he had attended a discussion on this subject and found on arrival that both Dr. Browning and himself had armed themselves with Carvill and Derby's statistics, which he thought very convincing. He gathered, however, from Dr. Browning's remarks that many ophthalmic surgeons were still sceptical of the value of specific treatment. He would like to suggest that possibly quicker results would be obtained by adjuvant treatment. Everyone knew of the value of pyrogenic therapy in syphilis affecting parts which were comparatively inaccessible to our specific remedies. He thought that either intravenous injections of T.A.B. or even malaria itself in conjunction with specific drugs might afford better results. Dr. Browning would recall that during the war, at Rochester Row, he had suggested sub-conjunctival injection of neosalvarsanised serum, and this treatment had been carried out 


\section{SYPHILITIC DISEASES OF THE EYE}

in a number of cases. He had thought the results fairly good, but the method of treatment had fallen into disuse.

Dr. HARDY KINGSTON asked whether either of the introducers had tried artificial sunlight in the kind of cases under discussion, as well as antisyphilitic remedies, and if so, with what results. Did they prefer artificial sunlight to X-ray therapy?

THE PRESIDENT felt very gratified that so many had taken part in the discussion, as many members probably felt that the subject was somewhat beyond their range.

The subject which had aroused most interest was interstitial keratitis, one which was of great importance. When the speaker was at the Ministry of Health one of the problems was as to the conditions under the V.D. Scheme which would justify the payment of a grant, and the view generally taken was that a grant from the Department was scarcely justifiable for expenditure on treatment of conditions which were not of considerable public health importance from the point of view of infectivity, and for which salvarsan treatment could not be expected to prove a cure. That was why it was felt that later manifestations in the nervous system, such as tabes and general paralysis, should not come under the scheme. It is true that since that time many clinicians have found that these diseases are not without response to energetic salvarsan treatment. The Ministry of Health, however, had to draw the line somewhere. Among the conditions which came into the problem was interstitial keratitis. Although the Ministry did not make a grant for interstitial keratitis in adults, they believed in giving every facility for the treatment of interstitial keratitis in children. At present it seemed that the experts were themselves divided as to whether salvarsan treatment was very beneficial in this condition. He did not think one should take a too pessimistic view because the second eye might develop interstitial keratitis while that condition was being treated in the first eye, as it was known that curious things occurred in the treatment of syphilis by arsenical preparations, such as a return of a positive Wassermann reaction. He was interested to hear Mr. Doyne say that interstitial keratitis was now less frequent than before the war; he did not know whether the reference was to the congenital variety, or 


\section{BRITISH JOURNAL OF VENEREAL DISEASES}

whether Mr. Doyne was speaking in a general way. Was any explanation given for this lessened frequency? $\mathrm{He}$ and the members of the Society would hope it was because the amount of congenital syphilis was being reduced, owing to sufferers coming earlier for treatment.

In the same connection Mr. Adams' remarks were of interest, because it would be agreed that if a syphilitic pregnant woman were treated she would produce a healthy baby; even if the baby were not entirely free from syphilis when born, this early treatment would reduce the total incidence of interstitial keratitis, for the disease would have been checked before that stage was reached.

Mr. Browning had made a remark which the speaker, as an old laboratory man, was glad to hear, because he thought that laboratory men were very proud of their work and regarded it as of high importance; but when the laboratory man said that laboratory observation could not replace clinical observation one felt that remark was true. The clinician must not expect to shift his diagnostic responsibility on to the laboratory worker. The function of the bacteriologist and the pathologist was to aid the clinician, and not to make the final diagnosis.

Mr. P. G. Doyne, in reply, said he was aware that ophthalmic surgeons were very old-fashioned, but from what Mr. Browning said one might think he, Mr. Browning, was a maltreated person. In Moorfields, however, everyone was in terror of him! The surgeons there got hauled over the coals if they did not at once send interstitial keratitis cases to be treated by him. The surgeon had to rely on his own diagnosis, but he hoped for Mr. Browning's help.

He did not wish it to be gathered, from what he said in his paper, that general treatment was useless. $\mathrm{He}$ thought that every ophthalmic surgeon always ordered treatment, but he stressed that from the pure point of view of eye treatment one could not say that general treatment would make all the difference to the case. Some of the mild cases cleared up quickly, but in the old days some of the mild cases cleared up quickly without treatment. He thought a better result was obtained with general treatment. However, it did not make all the difference in the world to the eye case. If one added 


\section{SYPHILITIC DISEASES OF THE EYE}

up the "full vision," "good vision" and " practical vision," the difference was not very enormous. The chief difference was seen in the "full vision " category.

In answer to Colonel Harrison's remark concerning iritis, Mr. Doyne admitted that statement was copied out of a book.

He was sure injury was an exciting cause of interstitial keratitis, but a large number of eye cases started without injury. Adopting Mr. Holmes Spicer's idea, that the disease was ready to start, and was only awaiting an incident to determine where, this certainly fitted in with clinical experience. No case had been reported in which the condition started in the non-traumatised eye, yet if the condition was ready to start in one eye, it might be assumed to be equally ready to start in the other eye. And in regard to the legal aspect, from the compensation point of view, injury could only be looked upon as the exciting cause, as strain was not supposed to be a cause of inguinal hernia, and that was held to be a parallel case.

With regard to the condition affecting the second eye, perhaps his own experience was unfortunate, but he could remember only one case in which the other eye had not been affected, except in atypical elderly cases, and acquired cases which were outside the usual age. As in the case of cataract, one never knew how quickly the condition would develop when it had started, and most of the success of vaunted treatments would be explained if there were control cases. X-ray treatment made the patient more comfortable, and sub-conjunctival injections would help, apart from the special effect.

He was rather ignorant about the other methods of treatment except that he understood that in some cases paracentesis of the anterior chamber immediately following intravenous injection had been carried out, but he did not know with what success. But here there was another "snag," because all corneal conditions were benefited by paracentesis of the anterior chamber.

With regard to the early signs of interstitial keratitis, usually it was the characteristic punctate condition, a haze starting from above and spreading downwards; sometimes starting centrally and spreading outwards. The commonest atypical commencement was that without any redness or vascularity of the eye, and there was no intolerance to light. And there was a type which 


\section{BRITISH JOURNAL OF VENEREAL DISEASES}

developed like a phlyctenule, and a small lesion occurred in the limbus, then it spread over and became interstitial keratitis. Those cases were not frequent, but they were disturbing.

It was his personal opinion that interstitial keratitis was now less common than previously, but he had no statistics to support it. A good deal depended on where one was situated. He was a house surgeon just before the war, and he thought he saw more interstitial keratitis then than now. It might be partly because many cases were not now seen by the ophthalmic surgeon.

He would be glad to know the value of the other tests for syphilis than the Wassermann. When one encountered a case of episcleritis, in which there was no clinical guide to its ætiology, how much value could be placed on the serological tests? There was the positive Wassermann, perhaps, and the condition might be anything ætiologically.

Mr. S. H. BRownING, in reply, said he always had the idea that in interstitial keratitis the Wassermann was negative in only 4 per cent. or 5 per cent., but he found the figure was 12 per cent.

He was almost glad to see the second eye becoming affected during treatment, for if it was, as appeared, inevitable that the second eye would be affected, then its appearance in that eye meant a quicker clearing up and much less damage than if it was affected after an interval. The intravenous injection of sodium iodide was reported to give extraordinarily good results, but he had not tried it.

That day he had talked to Mr. Duke-Elder about the effect of ultra-violet light or X-rays in interstitial keratitis, but he did not seem very enthusiastic about it, therefore probably the result was not very dramatic.

As to general treatment, there were other conditions to be looked out for in these cases, for the patients were often very badly nourished, and had glandular enlargements, so that cod-liver oil and similar treatment helped considerably.

In answer to Mr. Adams, interstitial keratitis was known to occur pre-natally, and he would like to know what method $\mathrm{Mr}$. Adams used in treating newly-born babies. It would seem to be difficult at that age. $\mathrm{He}$ agreed with Mr. Adams as to the need of early treatment ; 


\section{SYPHILITIC DISEASES OF THE EYE}

interstitial keratitis cases were not usually seen soon enough. It was of interest to him to hear that if syphilitics got eye trouble they did better than those who had not eye trouble.

He knew of no contra-indication to giving arsenic in eye trouble. He often treated irido-cyclitis of non-syphilitic origin with arsenical preparations, and with excellent results.

With regard to the effect of arsenic on other eye diseases, at one time he looked these cases up, and records of nearly' a million injections of arsenical preparations had been given and yet there was no bad effect on the eye at all.

Joint conditions were also commonly seen in these children with interstitial keratitis. Optic neuritis was rare as a syphilitic manifestation.

The importance of injury as a precursor to interstitial keratitis came up in regard to pensions after the war, and that point the President had dealt with.

As to why the second eye should become affected, often syphilitic lesions were absolutely symmetrical. Spirochætes had never been found locally. There were conditions in which one could not neglect the question of anaphylaxis. He did not know whether, one eye being affected, an anaphylactic reaction started, and that this spread to the cornea of the other eye. It might be on a par with sympathetic ophthalmitis. Iritis he looked upon as very rare in syphilis. Nearly all the cases of interstitial keratitis he had seen were also suffering from uveitis.

With regard to the sub-conjunctival injection of salvarsanised serum in interstitial keratitis, he was with Colonel Harrison at Rochester Row when he was trying that treatment, but he left before the cases were completed. Of 77 cases, there was improvement in 27 ; the speaker thought there was not very much improvement.

He was sorry the President was still unconvinced as to the benefit of treatment in interstitial keratitis; he would have thought the facts would have convinced Dr. Coutts. It was really a case of facts against prejudice.

With regard to the case which was mentioned by Colonel Harrison, of keratitis plus pus in the eye, the eye being washed out with perchloride, the speaker supposed that really was interstitial keratitis. Washing out in 


\section{BRITISH JOURNAL OF VENEREAL DISEASES}

that way would, in some cases, cause damage to the epithelium, with almost complete opacity of the cornea.

Mr. Doyne considered that interstitial keratitis was now less common than before the war, but the speaker found that the annual number of cases in the last two years was the same as twenty years ago. But, of course, so many cases of the condition might not have been sent to the laboratory in the first period.

The PRESIDENT conveyed the thanks of the Society to the openers of the discussion and those who had taken part in it. 